\title{
Can cost sharing contracts coordinate green supply chains based on manufacturers' overconfidence
}

\author{
Hui Zhou ${ }^{*} 1$ \\ ${ }^{1}$ College of Modern Economic \& Management, Jiangxi University of Finance and Economics, 330013 Nanchang Jiangxi, China
}

\begin{abstract}
Cost sharing contracts is one of the most common contracts to coordinate green supply chains. In this paper, we examine whether it can coordinate green supply chains in the set up of overconfidence. We assume that the manufacturer is overconfident and the retailer is rational. The manufacturer overestimates consumers' sensitivity to product greenness and accurately estimates the uncertainty of demand. The overconfident manufacturer and the rational retailer cooperate through cost sharing contracts. Then, we construct a game theoretical model to analyze the impact of manufacturers' overconfident on product greenness, pricing, profit and supply chain cooperation. At last, a numerical experimentation is presented. We find that, (1) the product greenness, wholesale price and retail price increase with the manufacturer's overconfidence as well as the retailer's cost sharing proportion. (2) no matter how much the cost sharing proportion is, the profit of manufacturers and retailers decreases with the manufacturer's overconfidence level. (3) cost sharing contracts can achieve the green supply chain coordination in rational setting. But under manufacturers' overconfidence, it cannot.
\end{abstract}

\section{Introduction}

Economic development has brought a series of problems such as environmental pollution and resource depletion, which has aroused the increasing concerns of consumers, enterprises and governments to green products. Consumers prefer to buy greener products, and enterprises have interest in producing products with a higher greenness. Meanwhile, governments impose more strict environmental constraints to reduce the environmental damage caused by manufacturers' production. Therefore, the implementation of green supply chain management has become an inevitable trend. There are many studies on green supply chain decisions and green supply chain coordination. Ghosh and Shah (2012) studied the influence of channel structure, greening cost and consumers' green sensitivity on product greenness, pricing and firms' profits and coordinated the green supply chain by using two-part pricing approach [1]. Zhang and Liu (2013) studied supply chain decisions under four game models in a three-level green supply chain, and discussed the coordination of green channel by revenue sharing contracts [2]. Ghosh and Shah (2015) studied green degree decisions and pricing of products in green supply chains, and coordinated the supply chain with revenue sharing contracts [3]. Xu et al. (2017) studied decisions of the green supply chain output and greenness under carbon trading constraints. They found wholesale price contracts and cost sharing contracts can achieve green

\footnotetext{
* Corresponding author: zhui0471@163.com
}

supply chain coordination [4]. Based on the wholesale price contracts, cost sharing contracts and two-part pricing contracts, Hong and Guo (2018) studied the decisions of product greenness and pricing, and compared and analyzed the greenness, price and profits among these contracts [5]. From the above research, we see that when decision-makers are rational, cost sharing contracts can effectively eliminate the impact of double marginalization and achieve the coordination.

However, the decision-makers are not completely rational. Overconfidence is a universal psychological behavior, and some scholars have found that decision-makers are overconfident in operation management. Schweitzer and Cachon (2000) studied the newsvendor's order decisions under different profit conditions through experiments, and found that the order quantity of newsboys deviates from the optimal order quantity that maximizes the expected profit [6]. Ren and Croson (2013, 2017) found that the newsvendor's decision bias may theoretically be caused by overconfidence, and confirmed this conclusion through experimental research [7,8]. Li et al. (2016) studied the impact of overconfidence on newsboy's decision in a competitive environment [9]. Xu et al. (2019) studied the impact of retailers' overconfidence on supply chain performance in a duopoly market composed of an overconfident retailer and a rational retailer selling the same products [10]. These literatures mainly focus on the impact of decision makers' overconfidence on non-green product in operation management. There are few literatures consider the impact of overconfidence behavior in green supply chain coordination. Does 
overconfidence affect the cost sharing contracts between manufacturers and retailers? If so, what impacts does it have? Hence, in this paper, we incorporate overconfidence into green supply chain coordination based on cost sharing contracts, to explore how the manufacturer's overconfidence affects product greenness, pricing, profits, and examine whether cost sharing contracts can achieve green supply chain coordination in overconfident environment.

The rest of this paper is organized as follow. Section 2 describes the problems and presents the model assumptions. In Section 3, we construct the model and provide the results of analysis. Numerical examples and sensitivity analysis are given in Section 4. Section 5 concludes the discussion.

\section{Problems Description and Model Assumptions}

This paper considers a green supply chain that consists of one overconfident manufacturer and one rational retailer. The overconfident manufacturer produces green products with greenness $g$ at a per-unit cost $c$. The rational retailer orders green products from the manufacturer at a wholesale price $\mathrm{w}$ and sells the product to consumers at a retailer price $\mathrm{p}$. The overconfident manufacturer cooperates with the rational retailer by cost sharing contracts. The retailer shares the proportion $\lambda$ of the greening investment with the manufacturer. To formulate the problem, we postulate following assumptions.

Assumption 1. The stochastic demand faced by the green supply chain is a linear function of the retail price and the product greenness. We use the following demand function that is similar to $[1,3]$ :

$$
\mathrm{d}=\mathrm{a}-\mathrm{bp}+\mathrm{kg}+\varepsilon
$$

where $\mathrm{a}>b c, \mathrm{~b}, \mathrm{k}>0$. In this equation, a represents the base market potential, b represents consumers' sensitivity to retail price, and $\mathrm{k}$ represents consumers' sensitivity to product greenness. $\varepsilon$ is a continuous random variable with mean 0 , and it reflects the uncertainty of demand.

Assumption 2. The manufacturer is overconfident, and he overestimates consumers' sensitivity and accurately estimates the uncertainty of demand. Thus, the demand function that the overconfident manufacturer deems is

$$
\mathrm{d}=\mathrm{a}-\mathrm{bp}+(1+\gamma) \mathrm{kg}+(1-\gamma) \varepsilon
$$

where $\gamma$ is the manufacturer's overconfidence level, $0 \leq \gamma \leq 1$. When $\gamma=0$ the manufacturer is rational; when $\gamma=1$ the manufacturer is completely overconfident.

Assumption 3. Greening ordinary products into green products requires capital investment. We assume that the greening investment is fixed costs and is related to the product greenness. Specially, assume the greening investment is $\operatorname{Ig}^{2} / 2$, I is the green investment cost coefficient. In the cooperation of cost sharing, greening investment is incurred by both the manufacturer and the retailer.

Assumption 4. The rational retailer knows the manufacturer's overconfident, but the manufacturer does not realize his overconfidence. Both manufacturers and retailers are risk neutral, and both seek to maximize their expected profits.

\section{Modeling and Solutions}

The sequence of decision making is in two steps. First, the overconfident manufacturer selects the product greenness $g$ and wholesale price $\mathrm{w}$ taking the proportion of cost sharing $\lambda$ into consideration. Then, the retailer decides the retail price according to product greenness and wholesale price. This is a two stage Stackelberg game.

The rational retailer's expected profit function is

$$
E \Pi_{\mathrm{R}}=(\mathrm{p}-\mathrm{w})(\mathrm{a}-\mathrm{bp}+\mathrm{kg})-\frac{\lambda \mathrm{Ig}^{2}}{2}
$$

The optimal retail price that maximizes the rational retailer's expected profit is

$$
\mathrm{p}(\mathrm{g}, \mathrm{w})=\frac{\mathrm{a}+\mathrm{bw}+\mathrm{kg}}{2 \mathrm{~b}}
$$

But the overconfident manufacturer deems that the demand the retailer faces is the same to him. Hence, the manufacturer considers that the retailer's expected profit is

$$
\mathrm{E} \Pi_{\mathrm{R}}^{\mathrm{o}}=(\mathrm{p}-\mathrm{w})[\mathrm{a}-\mathrm{bp}+(1+\gamma) \mathrm{kg}]-\frac{\lambda \mathrm{Ig}^{2}}{2}
$$

Maximizing equation (6), we get the retail price that the overconfident manufacturer deems

$$
\mathrm{p}^{\mathrm{o}}(\mathrm{g}, \mathrm{w})=\frac{\mathrm{a}+\mathrm{bw}+(1+\gamma) \mathrm{kg}}{2 \mathrm{~b}}
$$

The overconfident manufacturer deems his expected profit function is

$$
\mathrm{E} \Pi_{\mathrm{M}}^{\mathrm{o}}=(\mathrm{w}-\mathrm{c})[\mathrm{a}-\mathrm{bp}+(1+\gamma) \mathrm{kg}]-\frac{(1-\lambda) \mathrm{Ig}^{2}}{2}
$$

Therefore, substituting equation (6) into (7), we obtain the expected profit that the overconfident manufacturer naïvely thinks he derives

$$
\mathrm{E} \Pi_{\mathrm{M}}^{\mathrm{o}}=\frac{\mathrm{w}-\mathrm{c}}{2}[\mathrm{a}-\mathrm{bw}+(1+\mathrm{r}) \mathrm{kg}]-\frac{(1-\lambda) \mathrm{Ig}^{2}}{2}
$$

The first order conditions

$$
\begin{gathered}
\frac{\partial \mathrm{E} \Pi_{\mathrm{M}}^{\mathrm{o}}}{\partial \mathrm{g}}=\frac{\mathrm{k}(\mathrm{w}-\mathrm{c})(1+\gamma)}{2}-(1-\lambda) \operatorname{Ig} \\
\frac{\partial \mathrm{E} \Pi_{\mathrm{M}}^{\mathrm{o}}}{\partial \mathrm{w}}=\frac{\mathrm{a}+\mathrm{bc}-2 \mathrm{bw}+\mathrm{kg}(1+\gamma)}{2}
\end{gathered}
$$

The second order conditions

$$
\begin{gathered}
\frac{\partial^{2} \mathrm{E} \Pi_{M}^{o}}{\partial \mathrm{g}^{2}}=-(1-\lambda) \mathrm{I} \\
\frac{\partial^{2} \mathrm{E} \Pi_{\mathrm{M}}^{\mathrm{o}}}{\partial \mathrm{w}^{2}}=-\mathrm{b} \\
\frac{\partial^{2} \mathrm{E} \Pi_{\mathrm{M}}^{\mathrm{o}}}{\partial \mathrm{g} \partial \mathrm{w}}=\frac{(1+\gamma) \mathrm{k}}{2}
\end{gathered}
$$

When $b I(1-\lambda)>k^{2}$, the Hessian matrix of equation (8) is negative definite. Thus, there is a maximum of the overconfident manufacturer's naive profit. Equating the first order conditions to 0 we get

$$
\begin{aligned}
\mathrm{g}^{*} & =\frac{\mathrm{k}(1+\gamma)(\mathrm{a}-\mathrm{bc})}{4 \mathrm{bI}(1-\lambda)-\mathrm{k}^{2}(1+\gamma)^{2}} \\
\mathrm{w}^{*} & =\frac{2 \mathrm{I}(\mathrm{a}-\mathrm{bc})(1-\lambda)}{4 \mathrm{bI}(1-\lambda)-\mathrm{k}^{2}(1+\gamma)^{2}}+\mathrm{c}
\end{aligned}
$$

Substituting equations (14), (15) into (4), we get the retail price set by retailers

$$
\mathrm{p}^{*}=\frac{(\mathrm{a}-\mathrm{bc})\left[6 \mathrm{bI}(1-\lambda)-\mathrm{k}^{2} \gamma(1+\gamma)\right]}{2 \mathrm{~b}\left[4 \mathrm{bI}(1-\lambda)-\mathrm{k}^{2}(1+\gamma)^{2}\right]}+\mathrm{c}
$$

The actually expected profit that the overconfident manufacturer gets is 


$$
\mathrm{E} \Pi_{\mathrm{M}}=(\mathrm{w}-\mathrm{c})(\mathrm{a}-\mathrm{bp}+\mathrm{kg})-\frac{(1-\lambda) \mathrm{Ig}^{2}}{2}
$$

Substituting $\mathrm{g}^{*}, \mathrm{w}^{*}$ and $\mathrm{p}^{*}$ into equations (3) and (17) respectively, we obtain the actually profits of the retailer and manufacturer

$\mathrm{E} \Pi_{\mathrm{R}}^{*}=$

$\underline{(\mathrm{a}-\mathrm{bc})^{2}\left\{2 \mathrm{bI}\left[2 \mathrm{bI}(1-\lambda)^{2}-\mathrm{k}^{2} \lambda\right]+\mathrm{k}^{2} \gamma\left[\mathrm{k}^{2} \gamma(1+\gamma)^{2}-2 \mathrm{bI}(2+2 \gamma-\gamma \lambda)\right]\right\}}$ $4 \mathrm{~b}\left[4 \mathrm{bI}(1-\lambda)-\mathrm{k}^{2}(1+\gamma)^{2}\right]^{2}$

$$
\mathrm{E} \Pi_{\mathrm{M}}^{*}=\frac{\mathrm{I}(\mathrm{a}-\mathrm{bc})^{2}(1-\lambda)\left[4 \mathrm{bI}(1-\lambda)-\mathrm{k}^{2}(1+3 \gamma)(1+\gamma)\right]^{2}}{2\left[4 \mathrm{bI}(1-\lambda)-\mathrm{k}^{2}(1+\gamma)^{2}\right]^{2}}
$$

Proposition 1. The product greenness, wholesale price and retail price in the cost sharing contracts increase with the manufacturer's overconfidence.

Proof. According to equations (14) (16), we have $\frac{\partial \mathrm{g}^{*}}{\partial \gamma}=\frac{\mathrm{k}(\mathrm{a}-\mathrm{bc})\left[4 \mathrm{bI}(1-\lambda)+\mathrm{k}^{2}(1+\gamma)^{2}\right]}{\left[4 \mathrm{bI}(1-\lambda)-\mathrm{k}^{2}(1+\gamma)^{2}\right]^{2}}>0$,

$$
\begin{gathered}
\frac{\partial \mathrm{w}^{*}}{\partial \gamma}=\frac{4 \mathrm{Ik}^{2}(\mathrm{a}-\mathrm{bc})(1+\gamma)(1-\lambda)}{\left[4 \mathrm{bI}(1-\lambda)-\mathrm{k}^{2}(1+\gamma)^{2}\right]^{2}}>0, \\
\frac{\partial \mathrm{p}^{*}}{\partial \gamma}=\frac{\mathrm{k}^{2}(\mathrm{a}-\mathrm{bc})\left[4 \mathrm{bI}(1-\lambda)(2+\gamma)+\mathrm{k}^{2}(1+\gamma)^{2}\right]}{2 \mathrm{~b}\left[4 \mathrm{bI}(1-\lambda)-\mathrm{k}^{2}(1+\gamma)^{2}\right]^{2}}>0 .
\end{gathered}
$$

Because the sign of partial derivatives are positive, Proposition 1 is proved.

Proposition 1 indicates that, in the cost sharing contracts, the higher level of manufacturers' overconfidence, the larger greenness the product has. Higher overconfidence level leads the manufacturer charge a higher wholesale price. The increased greening investment caused by the improved greenness and increased wholesale price result in a higher retail price.

Proposition 2. The product greenness, wholesale price and retail price under manufacturers' overconfidence increase with the retailer's cost sharing proportion.

Proof. According to equations (14) (16), we derive

$$
\begin{aligned}
& \frac{\partial \mathrm{g}^{*}}{\partial \lambda}=\frac{4 \mathrm{bIk}(\mathrm{a}-\mathrm{bc})(1-\lambda)}{\left[4 \mathrm{bI}(1-\lambda)-\mathrm{k}^{2}(1+\gamma)^{2}\right]^{2}}>0 \\
& \frac{\partial \mathrm{w}^{*}}{\partial \lambda}=\frac{2 \mathrm{Ik}^{2}(\mathrm{a}-\mathrm{bc})(1+\gamma)^{2}}{\left[4 \mathrm{bI}(1-\lambda)-\mathrm{k}^{2}(1+\gamma)^{2}\right]^{2}}>0 \\
& \frac{\partial \mathrm{p}^{*}}{\partial \lambda}=\frac{\mathrm{Ik}^{2}(1+\gamma)(3+\gamma)(\mathrm{a}-\mathrm{bc})}{\left[4 \mathrm{bI}(1-\lambda)-\mathrm{k}^{2}(1+\gamma)^{2}\right]^{2}}>0
\end{aligned}
$$

For the sign of these partial derivatives, we get Proposition 2.

Proposition 2 shows that, under manufacturers' overconfidence, retailer share a part of greening cost is helpful to raise product greenness. It brings about higher wholesale and retail prices as well as the manufacturer's overconfidence. This conclusion is consistent with the situation when green supply chain members are complete rationality (Ghosh and Shah, 2015).

Proposition 3. The overconfident manufacturer's profit decreases with his overconfidence level in the cost sharing contracts.

Proof. Taking the first derivative of $E \Pi_{\mathrm{M}}^{*}$ with respect to $\gamma$, we obtain

$$
\frac{\partial \mathrm{E} \Pi_{\mathrm{M}}^{*}}{\partial \gamma}=-\frac{\mathrm{I}(\mathrm{a}-\mathrm{bc})^{2}(1-\lambda) \mathrm{k}^{2} \gamma\left[4 \mathrm{bI}(1-\lambda)+3 \mathrm{k}^{2}(1+\gamma)^{2}\right]}{\left[4 \mathrm{bI}-\mathrm{k}^{2}(1+\gamma)^{2}\right]^{3}} \geq 0 .
$$

The derivative equals 0 if and only if $\gamma=0$. Therefore, in the setting of cost sharing, when the overconfidence level increases, the manufacturer's profit decreases.

Proposition 3 indicates that, even in the cooperation of cost sharing, the manufacturer's overconfidence makes his own profit decline. Cost sharing contract cannot completely eliminate the negative impact of overconfidence on manufacturers. Whether cost sharing contracts can increase profits of the overconfidence manufacturer and the rational retailer? In our model, we cannot get the conclusion by algebraic analysis. In next section, we present numerical experimentation with the model developed to try to find some relevant conclusions.

\section{Numerical Experimentation}

In this section, a numerical example is provided to analyze the cross-effects of overconfidence and cost sharing on supply chain members. The related values are assumed as follows: $\mathrm{a}=1000, \mathrm{~b}=50, \mathrm{c}=6, \mathrm{I}=60$, $\mathrm{k}=20$. A sensitivity analysis is presented for different parameter values of the manufacturer's overconfidence level and the cost sharing proportion. The impact of the overconfidence level on the supply chain members' profits under different cost sharing proportion is given in Figure 1 and Figure 2.

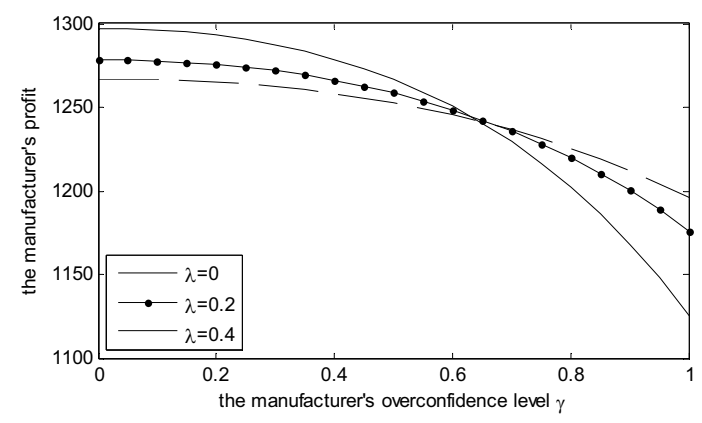

Figure 1. Cross-effects of overconfidence and cost sharing on the manufacturer's profit

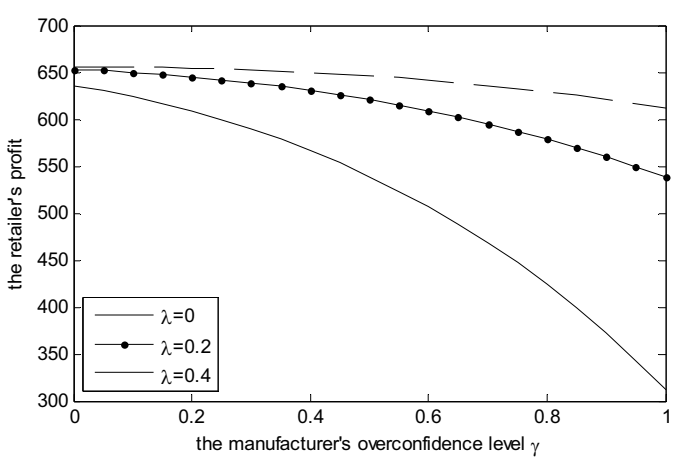

Figure 2. Cross-effects of overconfidence and cost sharing on the retailer's profit

From the two figures we can see, with an increase in $\gamma$, both the manufacturer and the retailer's profit decrease. There is a cross-effect between overconfidence and cost sharing. The lower the cost sharing proportion is, the faster the profit decreases with overconfidence level. For the overconfident manufacturer, when the overconfidence level is low, his profit under the lower cost sharing proportion is greater than that under the higher cost sharing proportion. But when the overconfidence level is high, the conclusion is opposite. For the rational retailer, sharing the greening investment cost with the overconfident manufacturer will only reduce his profit. The retailer will not benefit from the cooperation in cost sharing contracts. Hence, we find that, 
although cost sharing contracts can improve the product greenness, it cannot increase the overall profit of supply chain members, so it cannot achieve green supply chain coordination under overconfidence environment. This is not consistent with the conclusion under the rational environment.

\section{Conclusions}

As a common psychological behavior, overconfidence has an important impact on decision-making. In the framework of green supply chain cooperation based on cost sharing contract, this paper studies the green supply chain decisions when the manufacturer is overconfident, and explores the impact of manufacturers' overconfidence on supply chain decisions and profits. We find that, the product greenness, wholesale price and retail price increase with the manufacturer's overconfidence as well as the retailer's cost sharing proportion. Whatever the cost sharing proportion is, both the overconfident manufacturer and the rational retailer's profits are decreasing with the manufacturer's overconfidence level. Although the cost sharing contract can improve the manufacturer's profit when the manufacturer's overconfidence is low, it reduces the retailer's profit. When the manufacturer's overconfidence is high, the supply chain members' profits under cost sharing contracts are lower than that without contracts. Cost sharing in the setting of overconfidence makes the manufacturer and the retailer worse off. Hence, in a rational green supply chain environment, cost sharing contracts can achieve the coordination of green supply chains. But under manufacturer's overconfidence, cost sharing contracts cannot coordinate green supply chains.

\section{Acknowledgments}

The research was supported by the Science and Technology Research Project of Jiangxi Education Department of China (no. GJJ161551).

\section{References}

1. Ghosh D, Shah J. (2012) A comparative analysis of greening policies across supply chain structures. Int. J. Prod. Econ., 135(2): 568-583.

2. Zhang C T , Liu L. (2013) Research on coordination mechanism in three-level green supply chain under non-cooperative game. Appl. Math. Model., 37(5): 3369-3379.

3. Ghosh D, Shah J. (2015) Supply chain analysis under green sensitive consumer demand and cost sharing contract. Int. J. Prod. Econ., 164: 319-329.

4. $\mathrm{Xu} \mathrm{X,} \mathrm{He} \mathrm{P,} \mathrm{Xu} \mathrm{H,} \mathrm{et} \mathrm{al.} \mathrm{(2017)} \mathrm{Supply} \mathrm{chain}$ coordination with green technology under cap-and-trade regulation. Int. J. Prod. Econ., 183: 433-442.

5. Hong Z F, Guo X L. (2018) Green product supply chain contracts considering environmental responsibilities. Omega, 83(3):155 166.

6. Schweitzer ME, Cachon GP. (2000) Decision bias in the newsvendor problem with a known demand distribution: experimental evidence. Manage. Sci., 46(3): 404-420.

7. Ren Y, Croson R. (2013) Overconfidence in newsvendor orders: an experimental study. Manage. Scie., 59(11): 2502-2517.

8. Ren Y, Croson D, Croson R. (2017) The overconfident newsvendor. J. Oper. Res. Soc., 68(5): 496-506.

9. Li M, Petruzzi N, Zhang J. (2016) Overconfident competing newsvendors. Manage. Sci., 1-11.

10. Xu L, Shi X, Du P, et al. (2019) Optimization on pricing and overconfidence problem in a duopolistic supply chain. Comput. Oper. Res., 101: 162-172. 